\title{
FORUM
}

\section{A Note on the Kamal}

\section{from Professor E. G. R. Taylor}

AN important nautical manuscript in the Bibliotheque Nationale, Paris, containing a number of separate sections on Portuguese navigation methods, and written in the early sixteenth century, has been translated into modern Portuguese and edited by Professor Albuquerque of Coimbra.1 It is the Livro de Marinharia of André Pires, a Portuguese pilot only known by this collection, of a small part of which he was the actual author. The $13^{\text {th }}$ section, which is quite short, deals with the 'Balestilha of the Moors', i.e. the kamal. The use of this title confirms the point, for which there is some other evidence, that although the quadrant and the (sea) astrolabe were the official navigating instruments on Portuguese ships, the cross-staff or balestilha was known and used. The principle of the kamal was, of course, that of the cross-staff. A wooden rectangular tablet was held up with one edge on the horizon, the other on the heavenly body. A knotted cord running from the centre of the tablet was held taut between the observer's teeth, and all he had to know was the meaning of the knot in his mouth in terms of ports and landmarks. The first knot-nearest the tablet-measured the 'altura' of Mascat, which was east-west with Diulcende, on the coast of Diul in India. The fifth knot marked the altura of the Curia Muria Is., east-west with Dabul, and so on. A set of the knots from 1 to 7 , used with the tablet held upright, is listed, and this is followed by the pairs of names-including AdenBraçelor-indicated by six successive knots used with the tablet turned horizontally, in order to measure smaller altitudes conveniently. It has to be remembered that the Arabs only 'sailed down the latitude' when crossing the Arabian Sea. For positions along the African coast they observed the star Canopus. André Pires does, however, also give the equivalent of the knots in isbas, from which it appears that the Pole Star was observed at its lower meridian transit. This involved an appropriate addition to the observed height, and when the isbas in the Table are turned into degrees of the meridian it appears that this addition was approximately $5^{\circ}$, i.e. the Table was drawn up when the declination of the Pole Star was $95^{\circ} \mathrm{N}$. This must have been the correct figure in the thirteenth century, but by 1500 Polaris was only $3 \frac{1}{2}^{\circ}$ from the Celestial Pole, or even less. This, however, would be a matter of indifference to the navigator, provided that the maker of the kamal adjusted the knots so that the instrument 'read true'.

The relation between the isba and the degree was a simple one. For the purposes of navigation the circumference of the circle was divided into 224 isbas, so that each 'point' of the compass measured 7 isbas, instead of the awkward $117^{\circ}$ which the European sailor had to use. Thus one isba was equivalent to $I^{\circ} 36^{\prime} 25^{\prime \prime}$ and the ratio which Pires gives for turning a chart based on isbas into a chart with lines of latitude is to take every 5 isbas as 8 degrees. The error is 2' $05^{\prime \prime}$ approximately, which could be neglected.

It will be recalled that Vasco da Gama had a discussion with the Arab masterpilot Ibn Madjid at Melinde about their respective methods of navigation, and for a time the Portuguese actually made use of the kamal. But it only had a limited 
usefulness - the range of knots which André Pires tabulates covered latitudes only from $10^{\circ}$ to $24^{\circ}$-and laborious although it was, the meridian observation of the Sun, used with the four-year declination tables, was a sounder practice.

The sections of this manuscript (which has an English Introduction by Armando Cortesão) include the Regiment of the Sun, the Regiment of the Pole, the Regiment of the Southern Cross, the Length of an Arc of the Meridian and the Variation of the Compass. Its publication is an important addition to the source material for the History of Navigation. It is of interest, too, as having come into the possession of the French Minister Colbert as a gift from the French Ambassador to Lisbon.

\title{
REFERENCE
}

1 Luis Mendonça de Albuquerque, $O$ Livro de Marinharia de André Pires, Junta de Investigações do Ultramar, Lisboa, 1963.

\section{Radar Practice in Fairly Dense Traffic}

\author{
from Commander P. Clissold
}

THERE are occasions when, because of the density of shipping and/or lack of sea room, ships navigating by radar in thick weather cannot avoid passing within a distance of two miles, the least distance usually considered desirable. In such a situation a simple plan of procedure and of avoiding action, if possible to devise, should greatly reduce strain on the navigator and so increase the safety of navigation generally. Also, if such a plan came to be generally followed, safety would be further enhanced, because each navigator would know what the others were likely to do.

The plan described supposes that a ship has a relative display radar with a not less than 12 -inch screen, fitted with a reflection plotter.

The aim is to keep the procedure as simple and straightforward as possible, with the minimum amount of plotting. The method employed is as follows:

(a) Watch kept on 6-mile scale.

(b) Range marker kept at 5 miles range.

(c) Echoes are marked on the reflection plotter on appearance and periodically until the 5 -mile ring is reached.

(d) The distance of nearest approach is then estimated by laying a straight-edge along the line of the echo's advance.

(e) If the distance of the nearest approach is less than one mile, course is altered in accordance with Hollingdale's rules (rounded), which are based upon the bearing of the threat (Fig. I). If this rule cannot be safely applied because of, for example, the presence of another ship, engines are stopped. There are thus two simple actions open to the navigator: the first, usually taken, is to alter 